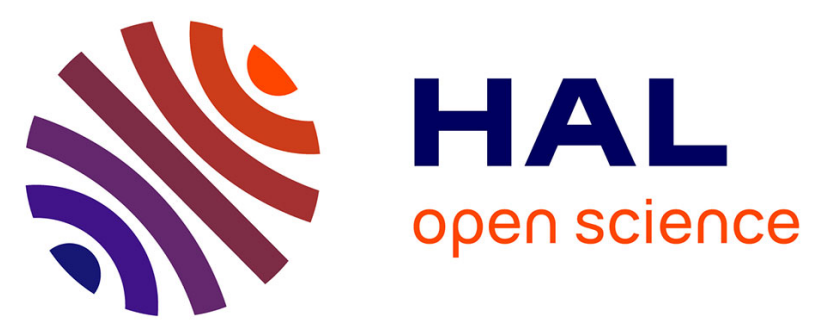

\title{
Synergy between polymorphism, pressure, spin-crossover and temperature in [Fe(PM-BiA)2(NCS)2]: a neutron powder diffraction investigation
}

Vincent Legrand, Stanislav Pechev, Jean-François Létard, Philippe Guionneau

\section{- To cite this version:}

Vincent Legrand, Stanislav Pechev, Jean-François Létard, Philippe Guionneau. Synergy between polymorphism, pressure, spin-crossover and temperature in [Fe(PM-BiA)2(NCS)2]: a neutron powder diffraction investigation. Physical Chemistry Chemical Physics, 2013, 15 (33), pp.13972-13880. 10.1039/C3CP51444G . hal-01007353

\section{HAL Id: hal-01007353 \\ https://hal.science/hal-01007353}

Submitted on 4 Mar 2018

HAL is a multi-disciplinary open access archive for the deposit and dissemination of scientific research documents, whether they are published or not. The documents may come from teaching and research institutions in France or abroad, or from public or private research centers.
L'archive ouverte pluridisciplinaire HAL, est destinée au dépôt et à la diffusion de documents scientifiques de niveau recherche, publiés ou non, émanant des établissements d'enseignement et de recherche français ou étrangers, des laboratoires publics ou privés. 


\title{
Synergy between polymorphism, pressure, spin-crossover and temperature in [Fe(PM-BiA $)_{2}(\mathrm{NCS})_{2}$ ]: a neutron powder diffraction investigation
}

\author{
Vincent Legrand, ${ }^{* a}$ Stanislav Pechev, ${ }^{\mathrm{b}}$ Jean-François Létard ${ }^{\mathrm{b}}$ and Philippe Guionneau ${ }^{\mathrm{b}}$
}

The pressure dependencies of the lattice parameters of the spin transition compound $\left[\mathrm{Fe}(\mathrm{PM}-\mathrm{BiA})_{2}(\mathrm{NCS})_{2}\right]$ have been derived from neutron powder diffraction measurements at low temperature. The study of the compound [Fe(PM-BiA $\left.)_{2}(\mathrm{NCS})_{2}\right]$-pl has first confirmed the atypical spin crossover behaviour under pressure of this compound that shows a pressure induced structural transition inducing the transformation into a different polymorph, $\left[\mathrm{Fe}(\mathrm{PM}-\mathrm{BiA})_{2}(\mathrm{NCS})_{2}\right]$-pll. This phenomenon avoids a first-order spin transition in favour of continuous transition around $0.75 \mathrm{GPa}$ at ambient temperature. Low temperature measurements under pressure up to $1.07 \mathrm{GPa}$ allowed us not only to describe the spin-crossover for both polymorphs but also to reach phase-diagram regions where both polymorphs co-exist in different spin-states. Finally, the reversibility of the structural variations has been demonstrated.

\section{Introduction}

Particular attention has been paid to spin transition compounds in the last twenty years. ${ }^{1-3}$ These materials are especially interesting owing to their bistability properties, which give them promising applications such as data storage elements, thermal switches, pigments or display devices. ${ }^{4-7}$ In iron(II) complexes, the spin conversion is related to the electronic configuration of the ion changing from $\mathrm{t}_{2 \mathrm{~g}}{ }^{6} \mathrm{e}_{\mathrm{g}}{ }^{0}$ in the low spin (LS) state to $\mathrm{t}_{2 \mathrm{~g}}{ }^{4} \mathrm{e}_{\mathrm{g}}{ }^{2}$ in the high spin (HS) state. This electron redistribution corresponds to drastic structural variations, principally observed in the iron-coordination sphere. In $\mathrm{FeN}_{6}$ based complexes, a decrease of the octahedron deformation and an increase of the Fe-ligand bond length $\left(\Delta r_{\mathrm{HL}} \sim 0.2 \AA\right)$ are typical for the HS $\rightarrow$ LS transition $^{8-11}$ leading to a $25 \%$ variation of the metal coordination sphere volume. Such a modification is then propagated to the whole crystal packing and to the crystal at any scale - from the molecule to the crystal packing - but with very variable amplitudes from one compound to another. Consequently, this phenomenon can be easily investigated using X-ray or neutron

\footnotetext{
${ }^{a}$ LUNAM Université, Université de Nantes - Ecole Centrale Nantes, Institut de Recherche en Génie Civil et Mécanique UMR CNRS 6183, Equipe Etat Mécanique et Microstructure, 37 boulevard de l'Université, BP 406, 44602 Saint-Nazaire cedex, France.E-mail: vincent.legrand@univ-nantes.fr

${ }^{b}$ CNRS, Univ. Bordeaux, ICMCB, UPR 9048, F-33600 Pessac, France
}

diffraction techniques. As notably shown by diffraction experiments, spin-crossover complexes can change their spin state upon the variation of a thermodynamic parameter such as temperature, ${ }^{12,13}$ pressure, ${ }^{14-17}$ intense magnetic field ${ }^{18}$ or light irradiation. ${ }^{19-23}$ It is well known that the spin conversion is associated with an entropy change and that the thermodynamically stable spin state at high temperature is the HS phase. ${ }^{24}$ When the temperature is decreased, the LS phase becomes thermodynamically stable and the thermal spin transition temperature $T_{1 / 2}$, where the LS and HS states are equally present in the material $\left(\gamma_{\mathrm{HS}}=\gamma_{\mathrm{LS}}=0.5\right)$, can be defined. Pressure effects on spin-crossover compounds have the issue of favouring the LS state due to their smaller volume, resulting in a shift of the transition temperature $T_{1 / 2}$ towards higher temperature in a smoother transition, an increase of the eventual LS residue and a reduction of the hysteresis width. ${ }^{25,26}$ However, many deviations from this ideal behavior have been observed and were generally attributed to a complex structural phase diagram under pressure. ${ }^{17,27}$

Most of the Fe(II) spin transition compounds studied under pressure have been investigated by spectroscopic measurements or magnetic experiments. ${ }^{28-34}$ Only 7 investigations have been performed by X-ray diffraction measurements on the compounds $\left[\mathrm{Fe}(\text { phen })_{2}(\mathrm{NCS})_{2}\right]$ and $\left[\mathrm{Fe}(\mathrm{btz})_{2}(\mathrm{NCS})_{2}\right],{ }^{35}\left[\mathrm{Fe}(\mathrm{PM}-\mathrm{TeA})_{2^{-}}\right.$ $\left.(\mathrm{NCS})_{2}\right] \cdot \mathrm{CH}_{3} \mathrm{OH},{ }^{36} \quad\left[\mathrm{Mn}(\text { pyrol })_{3}\right.$ tren $],{ }^{37} \quad\left[\mathrm{Fe}(\text { bapbpy })_{2}(\mathrm{NCS})_{2}\right],^{38}$ $\left[\mathrm{Fe}(\mathrm{dpp})_{2}(\mathrm{NCS})_{2}\right] \cdot \mathrm{py}^{16}$ and $\left[\left\{\mathrm{Fe}(\mathrm{bpp})(\mathrm{NCS})_{2}\right\}_{2}\left(4,4^{\prime}\right.\right.$-bipy $\left.)\right] \cdot 2 \mathrm{MeOH} .^{15}$ 


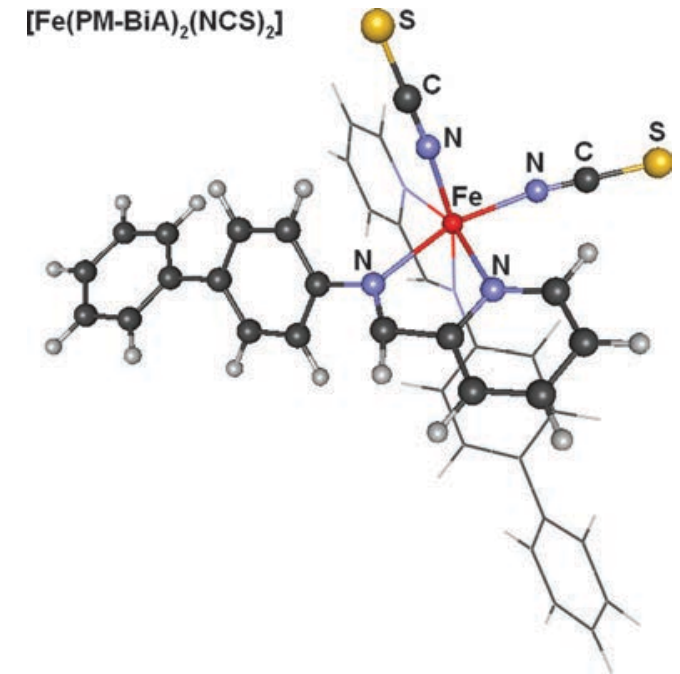

Fig. 1 Molecular structure of the spin transition complex $\left[\mathrm{Fe}(\mathrm{PM}-\mathrm{BiA})_{2}(\mathrm{NCS})_{2}\right]$ in the HS state at ambient temperature and pressure.

It can also be mentioned that only 1 study of spin crossover compounds under pressure using neutron scattering has been performed. ${ }^{14}$

Depending on the synthesis protocol the spin crossover complex $\left[\mathrm{Fe}(\mathrm{PM}-\mathrm{BiA})_{2}(\mathrm{NCS})_{2}\right] \quad(\mathrm{PM}=N$-2'-pyridylmethylene; $\mathrm{BiA}=4$-aminobiphenyl) (Fig. 1) crystallizes in two distinct polymorphs having very different spin crossover behaviors under ambient pressure conditions. ${ }^{39,40}$ The two polymorphs will be noted polymorph-I, labeled [Fe(PM-BiA $\left.)_{2}(\mathrm{NCS})_{2}\right]-p I$ (HS-I and LS-I), and polymorph-II, labeled [Fe(PM-BiA $\left.)_{2}(\mathrm{NCS})_{2}\right]-p I I$ (HS-II and LS-II), in the following. Polymorph-I shows an abrupt and complete thermal transition at around $T_{1 / 2}=170 \mathrm{~K}$ with a small hysteresis $(\Delta T=5 \mathrm{~K})$, attributed to a regular and compact intermolecular interaction network. This polymorph crystallizes in the orthorhombic space group $P c n^{39-41}$ with the lattice parameters at $300 \mathrm{~K}: a=12.962(5) \AA, b=15.223(5) \AA, c=$ 17.644(52) $\AA$ and $V=3482(2) \AA^{3}$. Polymorph-II, in contrast, exhibits a gradual thermal spin crossover without hysteresis, the crossover is centered at around $T_{1 / 2}=205 \mathrm{~K}^{42} \mathrm{Fe}(\mathrm{PM}-\mathrm{BiA})_{2}(\mathrm{NCS})_{2}$-pII crystallizes in the monoclinic space group $P 2{ }_{1} / c^{39,40,43}$ with the lattice parameters at $295 \mathrm{~K}: a=17.548(2) \AA, b=12.591(1) \AA, c=$ 17.338(2) $\AA, \beta=115.62(1)^{\circ}$ and $V=3454.1(6) \AA^{3}$. Magnetic measurements under pressure revealed that when increasing the pressure up to $0.6 \mathrm{GPa}$, polymorph-I exhibits a typical stabilization of the LS state with a reduction of the hysteresis. ${ }^{44}$ Surprisingly, in the pressure range of $0.6-0.8 \mathrm{GPa}$, the hysteresis increases strongly to reach $25 \mathrm{~K}$ and above $0.8 \mathrm{GPa}$ decreases again. Later, it was shown in a previous work, performed using neutron diffraction at room temperature and under hydrostatic pressure, ${ }^{14}$ that this behavior is attributed to a pressureinduced structural transition from polymorph-I to polymorph-II at around $P=0.75(5) \mathrm{GPa}$. That symmetry change avoids a firstorder spin transition in favor of a continuous transition. More recently, a pure theoretical approach based on DFT calculations has confirmed this pressure-induced polymorphism and an attempt on the $(P, T)$ phase diagram was proposed. ${ }^{45}$ The latter proposes an intricate interplay between polymorphism and spin states but lacked experimental data under high pressure at low temperature.

In the present work, the structural phase diagram of the spin transition compound $\left[\mathrm{Fe}(\mathrm{PM}-\mathrm{BiA})_{2}(\mathrm{NCS})_{2}\right]$ (Fig. 1) is investigated using neutron powder diffraction under pressures up to $1.07 \mathrm{GPa}$ at variable temperatures down to $130 \mathrm{~K}$. This combination of High Pressure-Low Temperature (HP-LT) environments gives the opportunity: (1) to experimentally confirm the previous neutron diffraction results related by Legrand et al. $(2008) ;{ }^{14}(2)$ to test experimentally the $(P, T)$ phase diagram proposed from DFT calculations and (3) to refine for the first time to our knowledge HP-LT neutron data for a spin crossover powder notably in the case where it contains a mixture of polymorphs with different spin states. The lattice parameter variations while applying high pressure and low temperature are described and confronted with the results obtained by magnetic measurements. ${ }^{44}$

\section{Experimental section}

Crystalline powders were synthesized following the usual method. ${ }^{39-41}$ The initial product corresponds to $\left[\mathrm{Fe}(\mathrm{PM}-\mathrm{BiA})_{2}\right.$ $(\mathrm{NCS})_{2}$ ]-pI. Neutron scattering measurements were performed at the Institut Laue-Langevin (Grenoble, France) using the twoaxis powder diffractometer $\mathrm{D} 20^{46}$ in high-flux configuration with a wavelength of $2.4 \AA$, equipped with a ROC (radial oscillating collimator) to minimize the background. The pressure cell was a TiZr clamped cell using Fluorinert liquid, i.e. hydrocarbon in which hydrogen is substituted by fluorine ("Fc75", 3M, St Paul, MN, USA), as the pressure transmitter. Inner volume of the pressure cell containing the sample (powder and Fluorinert) is about $550 \mathrm{~mm}^{3}$. The pressure cell was inserted into a He flow "orange" cryostat. It has been shown that Fluorinert "Fc75" remains a hydrostatic pressure medium at room temperature up to the maximum applied pressure used in the present studies. ${ }^{47,48}$ Nevertheless, no data are available in the literature concerning the hydrostatic behaviour of this pressure transmitting medium at low temperature and high pressure. We can only add a comment following a study we did on 3 other Fluorinert liquids, performed at high pressures and low temperatures using neutron diffraction: when the hydrostaticity is lost in the pressure cell, additional peaks appear in the diffraction pattern due to the solidification of the Fluorinert liquid. In particular, an intense peak grows in the 8-13 degrees $2 \theta$ range as pressure increases and temperature decreases (peak position depending on the studied liquids). In the present experiments we did not observe peaks of this kind; only at $1.07 \mathrm{GPa}$ and $260 \mathrm{~K}$ a tiny fluctuation of the background is observed at around $2 \theta=13$ degrees. As this very small fluctuation stays stable in intensity even at $130 \mathrm{~K}$, we could consider that the hydrostaticity is almost preserved all along the measurements. The experiments were performed at low temperature down to $130 \mathrm{~K}$ and at high pressure up to 1.07 GPa. For each set of measurements, the pressure is fixed at the required value and the temperature varies from room 
temperature to $130 \mathrm{~K}$ by cooling, then warming to room temperature again. Neutron diffraction measurements were performed during the two temperature variations (cooling and warming) in order to observe the reversibility of the thermal structural transitions at a given pressure. Uncertainties on temperature and pressure values are estimated to be $0.2 \mathrm{~K}$ and $0.05 \mathrm{GPa}$ respectively. Cell refinements were performed with the program Fullprof. ${ }^{49}$ Due to the used sample environment and the complexity of the compound molecular structure, it was not possible to go deeper in the refinement, especially to obtain further information about the atomic positions and thus, what would be of great interest, about the intra- and intermolecular bond lengths.

\section{Results and discussion}

In a previous neutron diffraction investigation ${ }^{14}$ of the compound $\left[\mathrm{Fe}(\mathrm{PM}-\mathrm{BiA})_{2}(\mathrm{NCS})_{2}\right]$, we reported that the application of a pressure of about $0.75(5) \mathrm{GPa}$ at ambient temperature induces a structural phase transition from polymorph pI to pII. This phase transition was observed only between the two HS states, thus between HS-I and HS-II, as only these species are stable at ambient temperature. The present challenge concerns the study of the HS to LS state transitions but also the investigation of the structural pI to pII transitions under high pressure and low temperature.

Recently, Rotaru et al. (2009) ${ }^{32}$ investigated by diffuse reflectivity the effect of hydrostatic pressure (1-1800 bar) on the thermal spin transition of $\left[\mathrm{Fe}(\mathrm{PM}-\mathrm{BiA})_{2}(\mathrm{NCS})_{2}\right]$-pI. They clearly showed that a progressive transformation into a new cooperative phase occurs in this pressure range. As the diffuse reflectance signature of this latter phase is different from the ones of polymorph pI and pII, they assigned without ambiguity the label pIII to the new structural phase. We have to mention here that the pressure range used in the study of Rotaru et al. is much lower than the pressure range available with the TiZr clamped cell used in the present neutron investigation or in Legrand et al. (2008). ${ }^{14}$ The configuration of the TiZr pressure cell used for neutron diffraction measurements makes that the smallest available hydrostatic pressure is around $0.15-0.20 \mathrm{GPa}$ at the best, by far higher than the pressure range investigated by diffuse reflectivity. Thus, we were not able to investigate the pIII phase here and a further diffraction measurement under pressure and variable temperature with a gas cell for example would be preferable. In addition, other differences were pointed out by Rotaru et al. through two comments: (1) "the surface behavior probed by diffuse reflectance may sizably differ from that of the bulk" and (2) "differences may also originate from the thermal history of the samples along the experiments". In the present neutron experiments, it is by essence the sample bulk that is probed and not the surface. Moreover, low temperature measurements were performed on different samples of the same set: one sample was used for pressures up to $0.74 \mathrm{GPa}$, another one was studied at $0.84 \mathrm{GPa}$ and a last sample was measured at 1.07 GPa. Thus, we are sure that the initial sample in the pressure cell was always in the HS-I state, then applying high pressure and low temperature induced the transformation into another state if it is appropriate, resulting in no thermal history effects. Despite it is interesting to investigate the latter in the general context of the fatigability of spin crossover materials, ${ }^{50}$ it was not the purpose of the present work.

As our study is performed at low temperature, we also have to discuss the recent work of Buron-Le Cointe et al. $(2012)^{42}$ on $\left[\mathrm{Fe}(\mathrm{PM}-\mathrm{BiA})_{2}(\mathrm{NCS})_{2}\right]$ polymorphs $\mathrm{pI}$ and pII. They reported the isobaric temperature variation of the volume of the unit cell for pI and pII both of which undergo an important thermal contraction (about - $170 \AA^{3}$ between ambient temperature and $120 \mathrm{~K}$ for both polymorphs). This thermal contraction is induced by the natural contraction of the crystal packing when decreasing temperature, but also results from the change in spin states in the vicinity of the $T_{1 / 2}$ temperature (about $70 \AA^{3}$ ). In the present work, however, the reported behaviors are influenced by the change in spin states, by the thermal contraction and in addition by the applied hydrostatic pressure. These three parameters must be seen here as a global constraint applied on the sample as the spin transition and the thermal contraction also induced a kind of internal pressure effect. Moreover, as the neutron diffraction measurements were performed at fixed temperature and pressure values, we snapped the studied compound under particular thermodynamic conditions. Thus, in the following, we will not discuss the separate dynamic effect of the temperature or the spin transition on the structural changes under pressure. For doing that, one must analyze at a given pressure the accurate variation of the lattice parameters as performed by Buron-Le Cointe et al. (2012) ${ }^{42}$ and repeat the measurement for several pressure values. Consequently, this latter discussion is not possible on the basis of neutron diffraction results as one measured data point takes about 4 hours (including changes in temperature and pressure) and a clear study of the temperature evolution of the volume of the unit cell under various pressures would be only reasonably feasible with a synchrotron source. In the present study, we can only compare the phase transformations between the HS and LS states and the pI and pII polymorphs to draw a $(P, T)$ phase diagram from our collected crystallographic data.

Neutron diffraction patterns of the complex [Fe(PM-BiA $\left.)_{2}(\mathrm{NCS})_{2}\right]$ demonstrated profound changes in both the Bragg peak intensity and position as a function of pressure. This indicates modifications in the atomic positions thus in bond lengths of the molecular structure and in the crystal packing resulting in a significant change in the lattice parameters. Lattice parameter refinements are relatively easy when only one HS or LS phase is present and in this case the difference curve between the observed intensity and the calculated intensity is very flat. But when the complex neutron pattern results from the addition of two phases (mixture phases HS and LS) or concerns the superposition of the polymorphs pI and pII on the same diagram, one must take a great care about the values of the refined parameters. In fact, it is quite possible to have a good calculation to observe a pattern match related to a totally improbable structural model.

In our case of superposition of polymorphs, the difference curve between the observed and calculated patterns shows little fluctuations. An example is shown in Fig. 2 representing the 


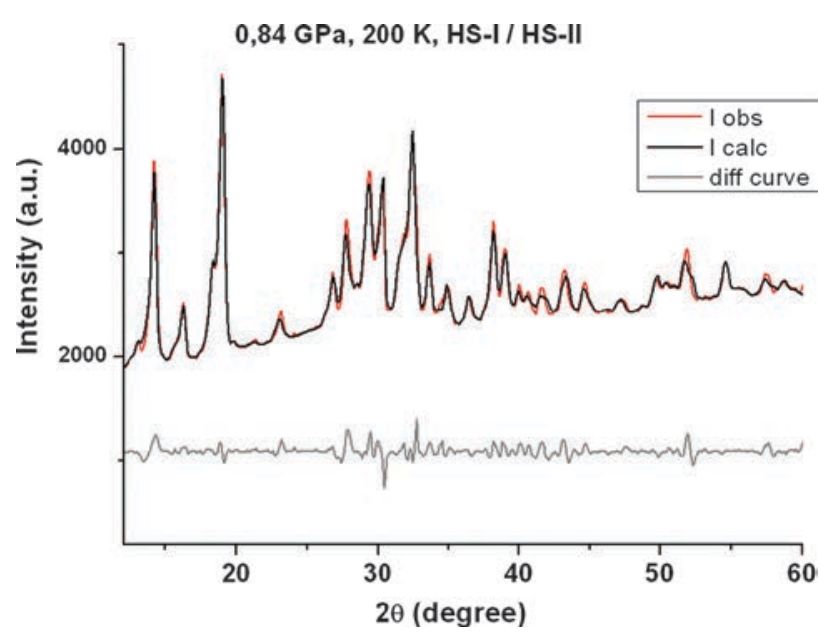

Fig. 2 Neutron diffraction data and Le Bail type refinement of the spin transition complex $\left[\mathrm{Fe}(\mathrm{PM}-\mathrm{BiA})_{2}(\mathrm{NCS})_{2}\right]$ at $0.84 \mathrm{GPa}$ and $200 \mathrm{~K}$. Under those thermodynamic conditions the powder material is composed of a mixture of the polymorphs $\mathrm{pl}$ and pll both in the HS state (HS-I and HS-II). Intensities of the observed data and of the calculated pattern are represented as well as the resulting differential curve.

refined data at $0.84 \mathrm{GPa}$ and $200 \mathrm{~K}$ where the $\mathrm{HS}$ states of both polymorphs are present. The calculated curve reproduces well the observed data. Polymorph pI crystallizes in an orthorhombic space group and polymorph pII in a monoclinic space group, thus each one of them shows its own specific anisotropic variation of the structural parameters as a function of pressure and temperature.

Finally, it can be observed on the neutron pattern in Fig. 2 and 3 that the background is not flat but characteristic of the sample environment with the coupling of the He orange cryostat with the clamped pressure cell.

The lattice parameters were refined and are reported in Table 1 for all measured pressures and temperatures.

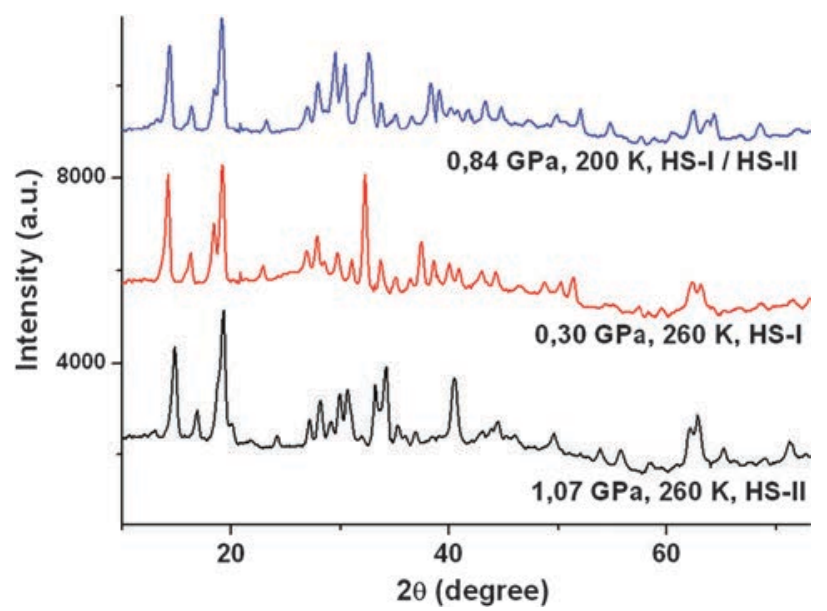

Fig. 3 Neutron diffraction patterns of the spin transition complex $\left[\mathrm{Fe}(\mathrm{PM}-\mathrm{BiA})_{2}(\mathrm{NCS})_{2}\right]$ measured under various conditions of pressure and temperature. From the bottom up are shown the neutron powder diffraction pattern corresponding to the HS state of polymorph pll (HS-II), polymorph pl (HS-I) and of the mixture of both phases.
They demonstrated an anisotropic and intricate evolution as a function of pressure and temperature (Fig. 4). At ambient pressure, the refined values of the lattice parameters for $\mathrm{pI}$ are in agreement with the literature and show a clear decrease of the volume from $3447(1) \AA^{3}$ in the HS state at $260 \mathrm{~K}$ to $3320(1) \AA^{3}$ in the LS state at $130 \mathrm{~K}$. As it is well known, this volume change is due to the sum of the pure thermal contraction and the spin crossover effects. ${ }^{43}$ At moderate pressures of 0.30(5) GPa and $0.60(5) \mathrm{GPa}$, the $\left[\mathrm{Fe}(\mathrm{PM}-\mathrm{BiA})_{2}(\mathrm{NCS})_{2}\right]$ system is still in the pI phase (orthorhombic, space group Pccn). For both pressures, the HS-I state is observed at $260 \mathrm{~K}$ and the compound stands in the LS-I state at $130 \mathrm{~K}$. A mixture of HS-I and LS-I phases in about 50\% proportion was also measured at 0.30(5) GPa and $187 \mathrm{~K}$ during the spin crossover. In other words, this means that the temperature of $187 \mathrm{~K}$ lies in the spin transition temperature domain for a pressure of $0.3 \mathrm{GPa}$. Since only a few temperatures were probed for each pressure value and since the HS-I to LS-I corresponds to a very sharp transition, it has been a lucky event to get this mixture. Note that even if the thermal evolution of the lattice parameters is well known at ambient pressure, ${ }^{42}$ it was very difficult to observe pI during the spin transition, i.e. where not all the ions are in the same spin state, as the accurate combination of pressure-temperature values must be obtained with regard to the abrupt spin transition. Anyway, at ambient pressure the spin transition occurs with $T_{1 / 2}=170 \mathrm{~K}$ in a temperature range narrower than $5 \mathrm{~K}$. The present study shows that at $0.3 \mathrm{GPa}$ the spin transition is on course at $187 \mathrm{~K}$ and that the latter almost corresponds to $T_{1 / 2}$ for this pressure. Thus as expected, the application of pressure induces a stabilization of the LS state and the thermal transition moves to higher temperature under pressure. In the present case, roughly, $T_{1 / 2}$ increases by $1 \mathrm{~K}$ for $150 \mathrm{bar}$.

In a previous work, ${ }^{14}$ we have shown that the pressure of $0.75(5) \mathrm{GPa}$ corresponds to about the limit of the polymorph transformation from pI into pII. In the present investigation, the refinement of the cell parameters at 0.74(5) GPa and $260 \mathrm{~K}$ confirms that the compound stays in the HS-I state. When pressure increases, at $260 \mathrm{~K}$, it can be noted for the HS-I state a significant variation of the $a$ and $b$ lattice parameters whereas the $c$ lattice parameter stays almost constant. At $260 \mathrm{~K}$, the HS-I cell volume progressively decreases from $3447(1) \AA^{3}$ at ambient pressure to $3353(1) \AA^{3}$ at $0.74(5)$ GPa (Fig. 4). In contrast, for the LS-I state at $130 \mathrm{~K}$, the anisotropic variation of the lattice parameters induces an increase of the cell volume when the pressure increases from $3320(1) \AA^{3}$ at ambient pressure to 3351(1) $\AA^{3}$ at $0.60(5)$ GPa (Fig. 4). An increase of the unit cell volume with increasing pressure is a non-intuitive situation but it has been already observed in spin-crossover systems leading to the concept of negative compression. ${ }^{15}$ Then the LS-I cell volume decreases to 3326(1) $\AA^{3}$ at 0.74(5) GPa. For that pressure of $0.74(5) \mathrm{GPa}$, the powder is composed of a mixture of HS-I and LS-I at $175 \mathrm{~K}$ in about the same proportions, corresponding thus to about $T_{1 / 2}$. This temperature is lower than that at $0.3 \mathrm{GPa}$. The decrease of $T_{1 / 2}$ when increasing pressure in this pressure range is in contradiction to a stabilization of the LS state when increasing pressure. However it is coherent with previous 


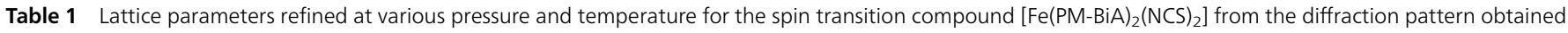
using neutron powder diffraction

\begin{tabular}{|c|c|c|c|c|c|c|c|}
\hline Pressure (GPa) & Temp. (K) & $a(\AA)$ & $b(\AA)$ & $c(\AA)$ & $\beta\left(^{\circ}\right)$ & $V\left(\AA^{3}\right)$ & Phase \\
\hline \multirow[t]{2}{*}{ Ambient } & 260 & $12.964(1)$ & $15.0975(6)$ & $17.6114(8)$ & & $3447(1)$ & HS-I \\
\hline & 130 & $12.3476(7)$ & $14.7227(4)$ & $18.2610(8)$ & & $3320(1)$ & LS-I \\
\hline \multirow[t]{5}{*}{0.3} & 260 & $12.961(2)$ & $15.1024(7)$ & $17.6273(9)$ & & $3450(1)$ & HS-I \\
\hline & 187 & $12.877(1)$ & $14.944(1)$ & $17.608(1)$ & & $3388(1)$ & HS-I (50.30\%) \\
\hline & & $12.408(2)$ & $14.717(2)$ & $18.328(6)$ & & $3347(1)$ & LS-I (49.70\%) \\
\hline & 130 & $12.461(1)$ & $14.722(1)$ & $18.287(1)$ & & $3355(1)$ & LS-I \\
\hline & 260 & $12.956(2)$ & $15.0923(8)$ & $17.629(1)$ & & $3447(1)$ & HS-I \\
\hline \multirow[t]{4}{*}{0.6} & 260 & $12.882(1)$ & $14.8819(8)$ & $17.611(1)$ & & $3376(1)$ & HS-I \\
\hline & 214 & $12.897(2)$ & $14.9001(8)$ & $17.609(1)$ & & $3384(1)$ & HS-I \\
\hline & 130 & $12.440(1)$ & $14.7424(7)$ & 18.271(1) & & $3351(1)$ & LS-I \\
\hline & 260 & $12.882(2)$ & $14.8730(8)$ & $17.619(1)$ & & $3376(1)$ & HS-I \\
\hline \multirow[t]{6}{*}{0.74} & 260 & $12.867(1)$ & $14.7799(7)$ & $17.632(1)$ & & $3353(1)$ & HS-I \\
\hline & 175 & $12.981(6)$ & $14.874(3)$ & $17.614(3)$ & & $3401(2)$ & HS-I (50.14\%) \\
\hline & & $12.512(6)$ & $14.898(6)$ & $18.143(7)$ & & $3382(1)$ & LS-I (49.86\%) \\
\hline & 130 & $12.3787(8)$ & $14.7276(7)$ & $18.243(1)$ & & $3326(1)$ & LS-I \\
\hline & 210 & $12.384(1)$ & $14.7312(8)$ & $18.252(1)$ & & $3330(1)$ & LS-I \\
\hline & 260 & $12.861(1)$ & $14.7688(7)$ & $17.634(1)$ & & $3349(1)$ & HS-I \\
\hline \multirow[t]{7}{*}{0.84} & 260 & $12.862(2)$ & $14.633(1)$ & $17.660(1)$ & & $3324(1)$ & HS-I \\
\hline & 200 & $12.862(4)$ & $14.823(2)$ & $17.668(3)$ & - & $3368(1)$ & HS-I (48.6\%) \\
\hline & & $17.89(6)$ & $12.476(4)$ & $17.60(4)$ & $115.0(2)$ & $3560(15)$ & HS-II (51.4\%) \\
\hline & 130 & $12.393(1)$ & $14.7265(7)$ & $18.243(1)$ & & $3329(1)$ & LS-I \\
\hline & 200 & $12.859(4)$ & $14.818(2)$ & $17.671(3)$ & - & $3367(1)$ & HS-I (44.9\%) \\
\hline & & $17.97(6)$ & $12.472(4)$ & $17.66(4)$ & $115.4(2)$ & $3574(14)$ & HS-II (55.1\%) \\
\hline & 260 & $12.858(1)$ & $14.6223(9)$ & $17.660(1)$ & & $3320(1)$ & HS-I \\
\hline \multirow[t]{7}{*}{1.07} & 260 & $17.663(4)$ & 12.701(3) & $17.405(2)$ & $115.112(8)$ & $3535(1)$ & HS-II \\
\hline & 210 & $17.656(8)$ & $12.592(8)$ & $17.551(8)$ & $116.19(3)$ & $3501(3)$ & HS-II (51.27\%) \\
\hline & & $17.395(6)$ & $12.430(5)$ & $17.071(4)$ & 115.61(2) & $3328(2)$ & LS-II $(48.73 \%)$ \\
\hline & 130 & $17.522(5)$ & $12.312(3)$ & $17.044(4)$ & $115.450(9)$ & $3320(2)$ & LS-II \\
\hline & 210 & $17.605(4)$ & $12.738(7)$ & $17.371(6)$ & $115.42(1)$ & $3518(2)$ & HS-II (51.19\%) \\
\hline & & $17.404(4)$ & $12.429(4)$ & $17.129(4)$ & 115.12(1) & $3354(1)$ & LS-II $(48.81 \%)$ \\
\hline & 260 & $17.678(3)$ & $12.710(3)$ & $17.413(2)$ & $115.097(7)$ & $3543(1)$ & HS-II \\
\hline \multirow[t]{2}{*}{0.17 (after 1.07) } & 260 & $12.850(1)$ & $14.600(1)$ & $17.663(1)$ & & $3314(1)$ & HS-I \\
\hline & 130 & $12.485(2)$ & $14.605(2)$ & $18.262(3)$ & & $3330(1)$ & LS-I \\
\hline
\end{tabular}

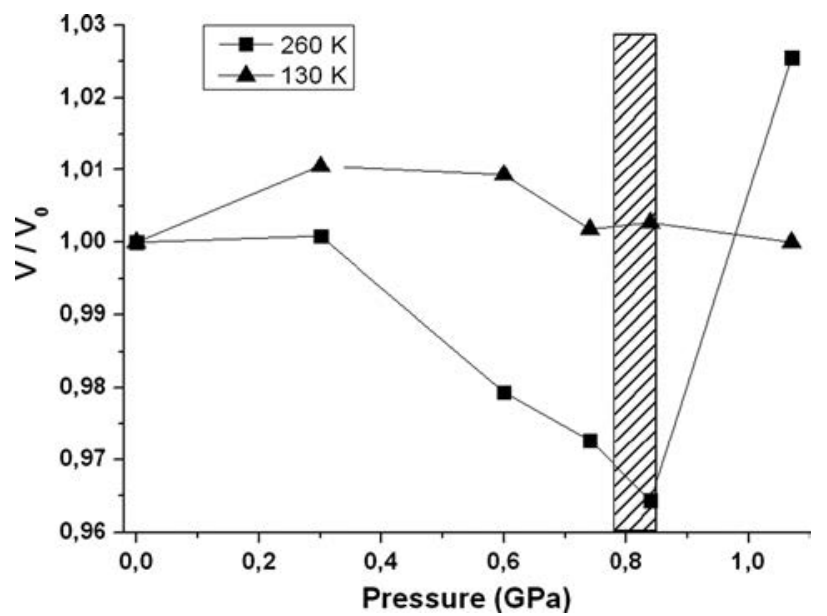

Fig. $4\left[\mathrm{Fe}(\mathrm{PM}-\mathrm{BiA})_{2}(\mathrm{NCS})_{2}\right]$ : relative pressure dependence of the volume measured at $260 \mathrm{~K}$ and $130 \mathrm{~K}$ by neutron diffraction. Dashed region at around $0.8 \mathrm{GPa}$ represents the structural transition region between polymorphs $\mathrm{pl}$ and pll.

magnetic data that yielded a reduction in the width of the hysteresis loop of the pI phase when increasing pressure up to $0.6 \mathrm{GPa}$. In addition, it was then noted that at higher pressure, the magnetic hysteresis width reaches about $25 \mathrm{~K}$ and subsequently presents a more gradual spin crossover. ${ }^{27,44}$ The latter behavior appears to be consistent with a pressureinduced transformation from pI to pII since the latter shows a gradual spin crossover. The present study confirms it is the case since the transformation of $\mathrm{pI}$ into $\mathrm{pII}$ is observed for pressure higher than 0.74(5) GPa. Indeed, diffraction patterns can be indexed with a superposition of HS-I and HS-II at 0.84(5) GPa. At higher pressure, 1.07(5) GPa, the diffraction pattern is indexed with the pII unit cell only showing the whole material has undergone a transformation from pI to pII (Table 1). Consequently, the present observation is consistent with the magnetic data since pII shows a gradual thermal spin crossover while pI shows hysteresis: at 0.74(5) GPa the molecular system is about to switch into the pII phase and the spin transition begins to be gradual, which has the effect to move $T_{1 / 2}$ toward lower temperatures as the hysteresis spreads significantly. At 0.84(5) GPa, the powder contains a mixture of HS-I and HS-II at $200 \mathrm{~K}$, in about half proportion and undergoes a full spin-crossover to the LS-I state at $130 \mathrm{~K}$ (Fig. 2). This unusual 
situation coming from a combination of the pI and pII phases may seem strange especially as the sole LS-I state is observed at $130 \mathrm{~K}$. However, this experimental result is coherent with the theoretical calculation of the phase diagram that predicted a possible direct conversion of HS-II in LS-I at low temperature and high pressure, even though the latter was expected at a slightly lower pressure range $(0.3 \mathrm{GPa}<P<0.7 \mathrm{GPa}) .{ }^{45}$ Furthermore, at $0.84 \mathrm{GPa}$ and $260 \mathrm{~K}$ the system is fully in HS-I, at $200 \mathrm{~K}$, however, the HS-II phase appears. This can be understood since decreasing the temperature corresponds to an increase of the internal pressure of the molecular system. The latter being sufficient at $0.84 \mathrm{GPa}$ to induce the partial appearance of the pII phase in the sample. Finally, at 1.07(5) GPa, the $\left[\mathrm{Fe}(\mathrm{PM}-\mathrm{BiA})_{2}(\mathrm{NCS})_{2}\right]$ complex is completely in the pII phase at any temperature showing a classical HS-II to LS-II spin crossover with $T_{1 / 2}$ around $200 \mathrm{~K}$. Indeed, after crossing the pI-to-pII transition pressure, once thus the sample is fully in HS-II, the variation of the unit-cell parameters is in perfect agreement with the values of the lattice parameters given for the HS-II to LS-II crossover. ${ }^{39}$

At this point we could add a comment. From the international tables of crystallography, the change in lattice parameters from an orthorhombic Pccn pI phase $\left(a_{\mathrm{I}}, b_{\mathrm{I}}, c_{\mathrm{I}}\right)$ to a monoclinic pII phase $\left(a_{\mathrm{II}}, b_{\mathrm{II}}, c_{\mathrm{II}}\right)$ is identified as a change in the translation symmetry basis. As shown in Fig. 5, the relationships between the two bases are $a_{\mathrm{I}}=b_{\mathrm{II}}, b_{\mathrm{I}}=-a_{\mathrm{II}}$ and $c_{\mathrm{I}}=c_{\mathrm{II}}$. One can notice that the $\left[\mathrm{Fe}(\mathrm{PM}-\mathrm{BiA})_{2}(\mathrm{NCS})_{2}\right]$ molecule is chiral and there are four enantiomers (two right-handed and two lefthanded) per unit cell. The molecular packing forms $2 \mathrm{D}$-sheets of molecules parallel to the $a c$ plane in the pI and parallel to the $b c$ plane in the pII polymorphs. Within a plane, the neighbouring molecules are symmetrical about the $2_{1}$ screw axis along the $a$ or $b$ crystallographic axes, respectively, in the pI or pII polymorphs. Thus, entities are arranged antiparallel in a sheet and form a zigzag along the $c$ crystallographic axis. A similarity between both polymorphs is also observed in the unit-cell volumes values of which are the same for the pI $\left(V=3462(2) \AA^{3}\right)$ and the pII $\left(V=3464(2) \AA^{3}\right)$ polymorphs ${ }^{39}$ as well as in the $\pi-\pi$ interaction network. As revealed by previous works, ${ }^{39,41}$ the differences between the orthorhombic and the monoclinic forms reside in a more distorted $\mathrm{FeN}_{6}$ octahedron and longer $\mathrm{S} \cdot \mathrm{H}$ (C) intermolecular hydrogen bonds for polymorph-pII. These small structural variations directly influence the properties of the spin crossover. Therefore, the pI to pII transition, which is observed in the present study, is not a simple transition between two polymorphs but a structural transition with symmetry breaking and group-subgroup relationship between both polymorphs. Thus, in the diffraction pattern new Bragg peaks due to the change in symmetry should be observed. In particular, in the pI phase, because of the Pccn space group, Bragg peaks indexed $(h k 0)$ with $h+k=2 n+1$ are forbidden by symmetry due to the $\mathrm{n}$ plane. These Bragg peaks should be observed in the pII phase. In the present case, the $h k l$ reflections list is generated from the " $p c r$ " Fullprof parameters file (with the known space group) and corresponding $h k l$ intensities are refined with the collected data. Checking the resulting files, we well observe that peaks indexed ( $h k 0)$ with $h+k=2 n+1$ are not present in the case of the pI phase and present in the case of the pII phase. This verification confirms the space group of each refined set of data and the nature of polymorphs pI or pII. The above polymorph transition discussion between pI and pII should be completed by a structural refinement of the pressure induced pII phase. This latter diffraction analysis, at low temperature and/or high pressure, on a single crystal should remove any doubt about the very nature of polymorph-II. However, measurement of this kind would be extremely complex to perform due to the difficulty in the crystallization process of polymorph-II and also in the achievement of such extreme condition experiment by neutron diffraction.

In the present study, we confirm that applying pressure on $\left[\mathrm{Fe}(\mathrm{PM}-\mathrm{BiA})_{2}(\mathrm{NCS})_{2}\right]-\mathrm{pI}$ induces a structural transition to a phase that corresponds to the second known polymorph of this complex, denoted $\left[\mathrm{Fe}(\mathrm{PM}-\mathrm{BiA})_{2}(\mathrm{NCS})_{2}\right]$-pII. The pI to pII pressure transition is estimated in this study to be around $0.84(5) \mathrm{GPa}$ at $260 \mathrm{~K}$, which is slightly higher than the value
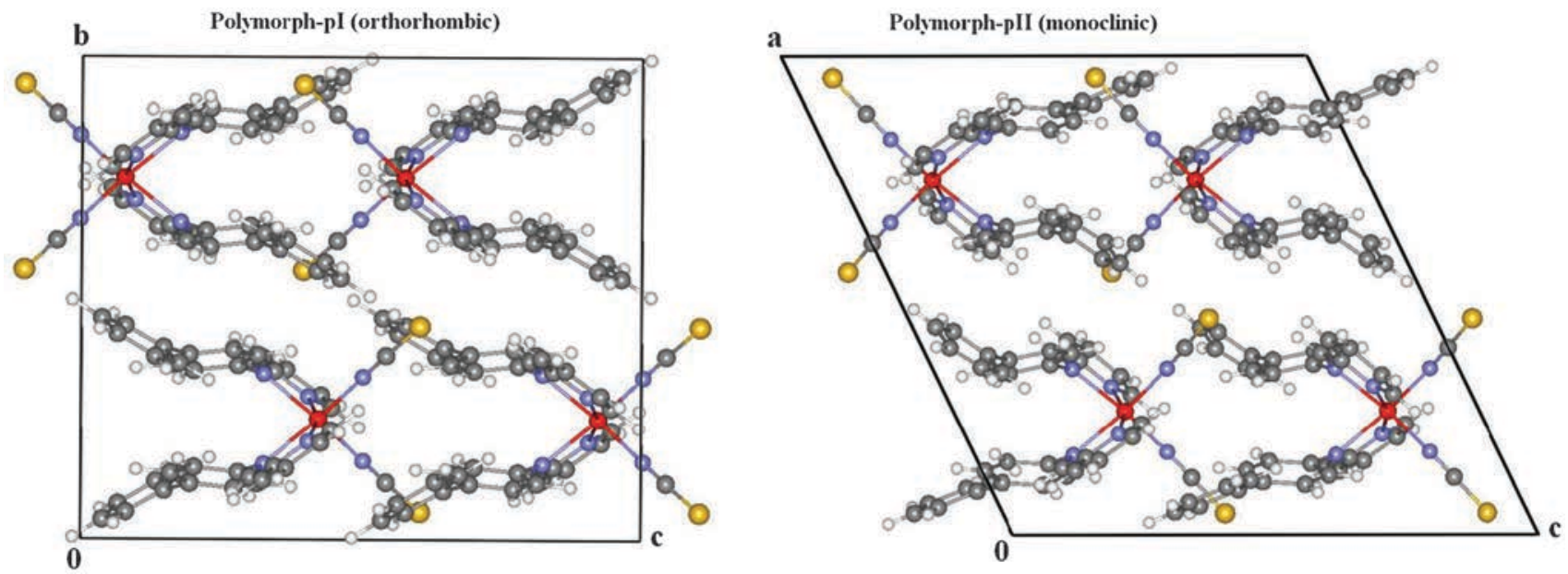

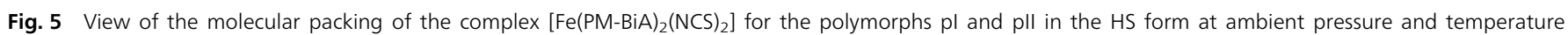
(crystallographic data from ref. 39). 
given in our previous neutron diffraction work performed at ambient temperature, but stays in a reasonable pressure range of around $0.8 \mathrm{GPa}$ as observed by magnetic measurements. ${ }^{44}$ Such transition was predicted from pure DFT consideration but expected to occur around $0.3 \mathrm{GPa}$ at $260 \mathrm{~K}$, thus at much lower pressure. ${ }^{45}$ This discrepancy is not surprising since in the latter calculation crystal packing effects are very difficult to take into account while they certainly play an important role in the pI to pII transformation in terms of pressure required.

Another interesting result concerns the reversibility of this pI to pII structural phase transition under pressure. After applying 1.07(5) GPa, the pressure was released in the cell to $0.17(5) \mathrm{GPa}$ (the piston inducing the pressure in the cell was completely removed and the resulting pressure was measured at the ILL Pressure Lab using a pressure gauge). The measured diffraction pattern and the refined lattice parameters well show (Table 1) that the system returns to its initial state, i.e. pI is again the stable phase. However, one can observe that the $a$ and $b$ lattice parameters of the HS-I state at $0.17(5) \mathrm{GPa}$ are contracted when compared to the one measured initially at ambient pressure. This can be explained by the fact that the pressure of $0.17(5)$ GPa was measured on the top surface of the sample inside the pressure cell, which could be different from the one really still effective in the bulk, i.e. in the probed volume by neutron diffraction. One indeed may conceive that the resultant pressure inside the $5 \mathrm{~mm}$ diameter cylinder containing the sample in the pressure cell could present a strong pressure gradient between bulk and the surface, especially after applying a high pressure of 1.07(5) GPa (the powder sample is compacted). When releasing the pressure in the cell, the pressure really operating on the sample decreased but stayed certainly at around $0.70 \mathrm{GPa}$ in the bulk regarding the values of the refined lattice parameters. Nevertheless, the reversibility of the pI to pII structural transition is well observed. Note also that the reversibility of the thermal spin-crossover was checked by investigating a full HS-LS-HS cycle at any pressure (Table 1).

This reversibility could ask questions about the (un)stability of the pII phase at ambient temperature and pressure. Indeed, in the present experiment, the pressure was released from $1.07(5)$ to $0.17(5) \mathrm{GPa}$ at ambient temperature. Thus, one may wonder why the pI phase is recovered and why pII is not stable at low pressure in the present case as it can be synthesized under normal $(P, T)$ thermodynamic conditions. The only assumption we could make is that even if the refinement confirms the space group and lattice parameters of a pII phase, the crystal packing of polymorph-II obtained at high pressure is certainly not exactly the same as the one stable under ambient $(P, T)$ conditions. The pressure induced pII phase would so have different weak intermolecular interactions, which would not favour this phase in relation to the pI phase. It is also well known that in phase transition long-range interactions (intraand intermolecular) play a key role too. As said before, a crystal structure refinement of the pressure induced pII phase from the pI phase should remove any doubt concerning the similitude of the present pII polymorph and the one already described in the literature. ${ }^{39}$

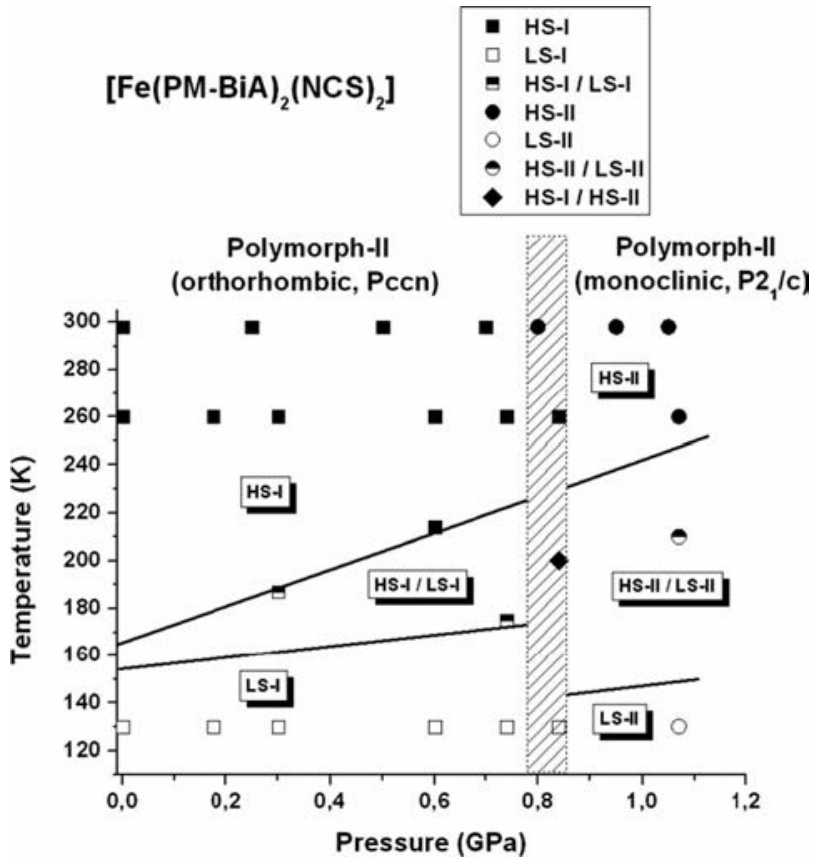

Fig. 6 Pressure-temperature phase diagram of the complex $\left[\mathrm{Fe}(\mathrm{PM}-\mathrm{BiA})_{2}(\mathrm{NCS})_{2}\right]$. All discrete points are determined from neutron diffraction data. Error bars on temperature and pressure are not indicated for clarity but are estimated to be $0.2 \mathrm{~K}$ and $0.05 \mathrm{GPa}$ respectively. Ambient temperature values are as determined in ref. 14. The solid lines are just a guide for the eyes, showing the transitions between spin states from the magnetic measurements as reported in Fig. 4 in ref. 44. Dashed region at around $0.8 \mathrm{GPa}$ represents the structural transition region between polymorphs $\mathrm{pl}$ and pll with a possible coexistence of both phases.

The pressure-temperature phase diagram of $\left[\mathrm{Fe}(\mathrm{PM}-\mathrm{BiA})_{2}(\mathrm{NCS})_{2}\right]$ is shown in Fig. 6. It is derived from neutron diffraction data (ILL, France) from our previous measurement at room temperature collected on $\mathrm{D} 2 \mathrm{~B}^{14}$ and from the present study performed at low temperature on D20. We added in Fig. 6 straight lines coming from magnetic data reported in Fig. 4 in Ksenofontov et al. (1998). ${ }^{44}$ These lines represent borders delimiting the pure HS and LS regions achieved by considering, respectively, the higher and lower values of the HS fraction as reported in ref. 44. We also included in Fig. 6 (dashed region) the pressure range where the transition behaviour reflects the presence of a mixture constituted of polymorphs pI and pII. All measured spin states from Table 1 are placed in the $(P, T)$ phase diagram and there is very good agreement between neutron diffraction and magnetic measurements. In the center of the established diagram, mixed HS-I-LS-I, HS-II-LS-II and HS-I-HS-II phases are observed across a large range of pressure and temperature. Consequently, looking at the pressure parameter, three regions must be defined: for $P<0.8$ GPa the HS-I $\leftrightarrow$ LS-I spin transition occurs, for $P \sim 0.8 \mathrm{GPa}$ the sequence is HS-I $\leftrightarrow$ HS-II $\leftrightarrow$ LS-I (with possible co-existent of the phases) and for $P>0.8 \mathrm{GPa}$ the HS-II $\leftrightarrow$ LS-II spin-crossover occurs.

This pressure-temperature phase diagram is atypical as it shows not only the isostructural spin transition of both orthorhombic and monoclinic polymorphs, but also the pressure induced structural phase transition between polymorphs. In its 
general features this phase diagram is coherent with the phase diagram derived from pure DFT calculations. In particular the direct conversion from HS-II to LS-I at high pressure is confirmed as well as the HS-I to HS-II transition. Pressure values for the pI to pII transition at variable temperature are not perfectly coherent between the experimental approaches and the theoretical one, experimental pressures being higher even though still in the same order of magnitude. This may be explained by on one side all the approximations made for the DFT calculation and on the other side all the experimental constraints that cannot be modelized (powder features such as size of the grain, hydrostaticity of the pressure. .). Moreover, as said before, the crystal packing effects play an important role during the thermal transition. This role is undoubtedly reinforced when applying pressure in addition to low temperature as both constraints modify, in a combined way, the crystallographic structure and the bond lengths, in particular concerning the $\mathrm{FeN}_{6}$ octahedra. Thus, the structural HS to LS state transition induces a modification of intra- and intermolecular electron density distribution when lowering temperature. ${ }^{22,51}$ It is also well known that $\pi-\pi$ and van der Waals interactions play a key role in the structural spin transition. All these interactions and electron redistributions are pressure-temperature interdependent and thus very difficult to estimate and to include in DFT calculations. Only an accurate analysis of the electron density, with topological analysis, performed at low temperature and high pressure would help to better predict the spin and phase conversions in the $(P, T)$ phase diagram. However, nowadays no electron density analysis of any molecular compound is resolved under pressure as the experimental conditions are so extreme (single crystal, low temperature, high pressure cell, high-resolution measurement within $\left.\sin \theta / \lambda>1 \AA^{-1} \ldots\right)$.

\section{Conclusions}

The present study reports for the first time a spin transition behaviour investigated at high hydrostatic pressure and low temperature using neutron diffraction. The obtained results confirm that a structural phase transition from the orthorhombic to the monoclinic symmetry occurs at about $0.8 \mathrm{GPa}$, i.e. from $\mathrm{pI}$ to $\mathrm{pII}$ polymorph. They also demonstrate the reversibility of the structural phase transition. The collected neutron diffraction data allowed us to plot the pressuretemperature phase diagram of the spin crossover complex $\left[\mathrm{Fe}(\mathrm{PM}-\mathrm{BiA})_{2}(\mathrm{NCS})_{2}\right]$. However, neutron powder diffraction technique in the case of combined high pressure and low temperature measurements shows a structural refinement limit, leading only to unit-cell parameters. It would be interesting in near future to perform similar measurements with a single crystal, by neutron or X-ray diffraction, to describe with accuracy the full crystallographic structure and the variation of the bond lengths, in particular in the coordination sphere surrounding the metal. Indeed, inter- and intra-molecular interactions play a key role in the behaviour of the spin crossover and in the induced properties (optical, magnetic...) of the compound. Investigations of this kind are fundamental for the elucidation of the effect of pressure on the occurrence of spin crossover properties. In the present case, through the structural study of the pressure-induced polymorphism of $\left[\mathrm{Fe}(\mathrm{PM}-\mathrm{BiA})_{2}(\mathrm{NCS})_{2}\right]$, it has been possible to demonstrate that beyond the crucial importance of the crystal field, the pressure plays a key role that must be taken into account for the spin crossover properties. Finally, developing such projects in the field of crystallography under extreme conditions could lead in a few years to get results under even more extreme conditions by adding a high magnetic field or a light irradiation to the actual conditions of pressure and temperature. ${ }^{52}$ Extreme condition measurements are always a challenge which must also be overcome in the field of the spin crossover phenomenon.

\section{Acknowledgements}

Experiments at the ILL were supported by a beamtime allocation from the College 5 Science and Technology Council.

\section{References}

1 Topics Curr. Chem, ed. P. Gütlich and H. A. Goodwin, Springer-Verlag, Berlin, 2004, pp. 233-235.

2 P. Gütlich, A. Hauser and H. Spiering, Angew. Chem., Int. Ed. Engl., 1994, 33, 2024-2054.

3 M. A. Halcrow, in Spin-Crossover Materials: Properties and Applications, ed. M. A. Halcrow, John Wiley \& Sons Ltd, Oxford UK, 2013, ISBN: 978-1-119-99867-9.

4 O. Kahn and C. J. Martinez, Science, 1998, 279, 44-48.

5 J.-F. Létard, P. Guionneau and L. Goux-Capes, Top. Curr. Chem., 2004, 235, 221-249.

6 A. Bousseksou, G. Molnár, L. Salmon and W. Nicolazzi, Chem. Soc. Rev., 2011, 40, 3313.

7 G. Aromi, L. A. Barros, O. Roubeau and P. Gamez, Coord. Chem. Rev., 2011, 255, 485-546.

8 L. Wiehl, G. Kiel, C. P. Köhler, H. Spiering and P. Gütlich, Inorg. Chem., 1986, 25, 1565-1571.

9 L. Wiehl, H. Spiering, P. Gütlich and K. Knorr, J. Appl. Crystallogr., 1990, 23, 151-160.

10 P. Guionneau, M. Marchivie, G. Bravic, J.-F. Létard and D. Chasseau, Top. Curr. Chem., 2004, 234, 97-128.

11 M. A. Halcrow, Chem. Soc. Rev., 2011, 40, 4119.

12 C. Lecomte, E. Aubert, V. Legrand, F. Porcher, S. Pillet, B. Guillot and C. Jelsch, Z. Kristallogr., 2005, 220(4), 373-384.

13 V. Legrand, C. Carbonera, S. Pillet, M. Souhassou, J.-F. Létard, P. Guionneau and C. Lecomte, J. Phys.: Conf. Ser., 2005, 21, 73-80.

14 V. Legrand, F. Le Gac, P. Guionneau and J.-F. Létard, J. Appl. Crystallogr., 2008, 41, 637-640.

15 H. J. Shepherd, T. Palamarciuc, P. Rosa, P. Guionneau, G. Molnar, J.-F. Létard and A. Bousseksou, Angew. Chem., Int. Ed., 2012, 51, 1-6.

16 H. J. Shepherd, P. Rosa, L. Vendier, N. Casati, J.-F. Létard, A. Bousseksou, P. Guionneau and G. Molnar, Phys. Chem. Chem. Phys., 2012, 14, 5265-5271.

$17 \mathrm{P}$. Guionneau and E. Collet, in Piezo- and photo-crystallography applied to spin-crossover materials. Spin-Crossover 
Materials: Properties and Applications, ed. M. A. Halcrow, John Wiley \& Sons Ltd, Oxford UK, 2013, ch. 20, pp. 507-526, ISBN: 978-1-119-99867-9.

18 A. Goujon, B. Gillon, A. Gukasov, J. Jeftic, Q. Nau, E. Codjovi and F. Varret, Phys. Rev. B: Condens. Matter Mater. Phys., 2003, 67, 220401.

19 M. Marchivie, P. Guionneau, J. A. K. Howard, G. Chastanet, J.-F. Létard, A. E. Goeta and D. Chasseau, J. Am. Chem. Soc., 2002, 124, 194-195.

20 A. Goujon, B. Gillon, A. Debede, A. Cousson, A. Gukasov, J. Jeftic, G. McIntyre and F. Varret, Phys. Rev. B: Condens. Matter Mater. Phys., 2006, 73, 104413.

21 V. Legrand, S. Pillet, H.-P. Weber, M. Souhassou, J.-F. Létard, P. Guionneau and C. Lecomte, J. Appl. Crystallogr., 2007, 40, 1076-1088.

22 S. Pillet, V. Legrand, H.-P. Weber, M. Souhassou, J.-F. Létard, P. Guionneau and C. Lecomte, Z. Kristallogr., 2008, 223, 235-249.

23 E. Collet, N. Moisan, C. Baldé, R. Bertoni, E. Trzop, C. Laulhé, M. Lorenc, M. Servol, H. Cailleau, A. Tissot, M.-L. Boilot, T. Graber, R. Henning, P. Coppens and M. Buron-Le Cointe, Phys. Chem. Chem. Phys., 2012, 14, 6192-6199.

24 M. Sorai and S. Seki, J. Phys. Chem. Solids, 1974, 35, 555-570.

25 A. Ewald, R. Martin, E. Sin and A. White, Inorg. Chem., 1969, 8, 1837-1846.

26 C. P. Slichter and H. G. Drickamer, J. Chem. Phys., 1972, 56, 2142-2160.

27 P. Gütlich, V. Ksenofontov and A. B. Gaspar, Coord. Chem. Rev., 2005, 249, 1811-1829.

28 J. Jeftic, H. Romstedt and A. Hauser, J. Phys. Chem. Solids, 1996, 57, 1743-1750.

29 J. Jeftic and A. Hauser, J. Phys. Chem. B, 1997, 101, 10262-10270.

30 J. Jeftic, R. Hinek, S. C. Capelli and A. Hauser, Inorg. Chem., 1997, 36, 3080-3087.

31 V. Ksenofontov, A. B. Gaspar and P. Gütlich, Top. Curr. Chem., 2004, 235, 23-64.

32 A. Rotaru, F. Varret, E. Codjovi, K. Boukheddaden, J. Linares, A. Stancu, P. Guionneau and J.-F. Létard, J. Appl. Phys., 2009, 106, 053515.

33 A. Rotaru, J. Linares, F. Varret, E. Codjovi, A. Slimani, R. Tanasa, C. Enachescu and A. Stancu, Phys. Rev. B: Condens. Matter Mater. Phys., 2011, 83, 224107.

34 G. G. Levchenko, G. V. Bukin, A. B. Gaspar and J. A. Real, Russ. J. Phys. Chem. A, 2008, 83, 951-954.
35 T. Granier, B. Gallois, J. Gaultier, J.-A. Real and J. Zarembowitch, Inorg. Chem., 1993, 32, 5305-5312.

36 P. Guionneau, C. Brigouleix, Y. Barrans, A. E. Goeta, J.-F. Létard, J. A. K. Howard, J. Gaultier and D. Chasseau, C. R. Acad. Sci. Paris, Chimie/Chemistry, 2001, 4, 161-171.

37 P. Guionneau, M. Marchivie, Y. Garcia, J. A. K. Howard and D. Chasseau, Phys. Rev. B: Condens. Matter Mater. Phys., 2005, 72, 214408.

38 H. J. Shepherd, S. Bonnet, P. Guionneau, S. Bedoui, G. Garbarino, W. Nicolazzi, A. Bousseksou and G. Molnar, Phys. Rev. B: Condens. Matter Mater. Phys., 2011, 84, 144107.

39 M. Marchivie, P. Guionneau, J.-F. Létard and D. Chasseau, Acta Crystallogr., Sect. B: Struct. Sci., 2003, 59, 479-486.

40 J.-F. Létard, G. Chastanet, O. Nguyen, S. Marcén, M. Marchivie, P. Guionneau, D. Chasseau and P. Gütlich, Monatshefte für Chemie, 2003, 134, 165-182.

41 J.-F. Létard, P. Guionneau, L. Rabardel, J. A. K. Howard, A. E. Goeta, D. Chasseau and O. Kahn, Inorg. Chem., 1998, 37, 4432-4441.

42 M. Buron-Le Cointe, J. Hébert, C. Baldé, N. Moisan, L. Toupet, P. Guionneau, J.-F. Létard, E. Freysz, H. Cailleau and E. Collet, Phys. Rev. B: Condens. Matter Mater. Phys., 2012, 85, 064114.

43 P. Guionneau, M. Marchivie, G. Bravic, J.-F. Létard and D. Chasseau, J. Mater. Chem., 2002, 12, 2546-2551.

44 V. Ksenofontov, G. Levchenko, H. Spiering, P. Gütlich, J.-F. Létard, Y. Bouhedja and O. Kahn, Chem. Phys. Lett., 1998, 294, 545-553.

45 A. Marbeuf, S. F. Matar, P. Négrier, L. Kabalan, J.-F. Létard and P. Guionneau, Chem. Phys., 2013, 420, 25-34.

46 T. C. Hansen, P. F. Henry, H. E. Fischer, J. Torregrossa and P. Convert, Meas. Sci. Technol., 2008, 19, 034001.

47 T. Varga, A. P. Wilkinson and R. J. Angel, Rev. Sci. Instrum., 2003, 74, 4564-5466.

48 V. A. Sidorov and R. A. Sadykov, J. Phys.: Condens. Matter, 2005, 17, S3005-S3008.

49 J. Rodriguez-Carvajal, Physica B, 1993, 192, 55-69.

50 P. Guionneau, S. Lakhloufi, M.-H. Lemée-Cailleau, G. Chastanet, P. Rosa, C. Mauriac and J.-F. Létard, Chem. Phys. Lett., 2012, 542, 52-55.

51 V. Legrand, S. Pillet, M. Souhassou, N. Lugan and C. Lecomte, J. Am. Chem. Soc., 2006, 128, 13921-13931.

52 V. Legrand, in Crystallography under extreme conditions: state of the art and perspectives. Recent Advances in Crystallography, ed. J. B. Benedict, Publisher: Intech, 2012, ch. 2, pp. 39-66, DOI: 10.5772/48608, ISBN: 978-953-51-0754-5. 